\section{The retail environment for tobacco: a barometer of progress towards the endgame}

\author{
Lisa Henriksen
}

This e-issue is the first devoted to the retail environment for tobacco products. It features research about regulating the consumer environment (packaging, labelling, and marketing) and the built environment (the quantity, type and location of retailers). The contents include studies from Australia, Canada, France, Greece, India, Lebanon, Mexico, New Zealand, Scotland, Switzerland, UK and USAcountries in which the consumer environment for tobacco differs markedly. In the USA, for example, stores that sell tobacco contain an average of 26 tobacco marketing materials (including branded signs and shelving units), and most advertise at least one discount, such as a special price for a multipack purchase. ${ }^{1} \quad$ Conspicuously located near the cash register, a typical powerwall contains an average of 124 cigarette pack facings ${ }^{2}$ and makes a colourful display of deadly products with some of the world's smallest, weakest warning statements on the least visible (side) panel. Antitobacco signage, if any, is limited to age-of-sale warnings, some of which were created by the industry to promote corporate image. $^{2} 3$

In many other countries, regulation of the consumer environment for tobacco indicates substantially more progress towards the endgame. ${ }^{4-6}$ Approximately one-third of countries ban tobacco advertising at the point of sale, and 15 of these ban retail displays, as well. ${ }^{7}$ Almost $40 \%$ of all countries have adopted pictorial warnings on packaging. In Australia, plain packaging has displaced the tobacco industry's use of colour to cue consumers about brand, flavour, strength, and relative harm of tobacco products, ${ }^{8}$ and several other countries are pursuing this new standard. ${ }^{9}$

While the consumer environment illustrates considerable variation in marketing regulations from country to country, the built environment for tobacco indicates too little progress towards regulation everywhere. Tobacco retailers are

Correspondence to Dr Lisa Henriksen, Stanford Prevention Research Center, Stanford University School of Medicine, Palo Alto, CA, 94304, USA;

Ihenriksen@stanford.edu ubiquitous in every country, and policies to restrict their quantity, type, and location could hasten the endgame.

\section{REGULATING THE CONSUMER ENVIRONMENT}

\section{Packaging and labelling}

Australia's implementation of plain packaging and the potential synergy with pictorial warnings is an important focus of this issue. Evidence from retail audits refutes the industry's claims that plain packaging harms retail businesses by increasing time to retrieve packs ${ }^{10}$ and by increasing the availability of illicit tobacco at the point of sale. ${ }^{11}$ Another study highlights concerns about industry-funded research that misused smoking prevalence data to conclude that plain packaging did not reduce smoking. ${ }^{9}$

Two studies describe the industry's use of colours, colour terms and pack size to microsegment the consumer market before and after plain packaging, highlighting important considerations for future regulation. ${ }^{12} 13$ In addition, a study with users of roll-your-own tobacco suggests that the impact of plain packaging on brand attachment and user satisfaction could extend to tobacco products other than factory-made cigarettes. ${ }^{14}$ In a message-testing experiment with US young-adult smokers, plain packaging enhances the impact of graphic imagery when combined with gain-framed messages about the benefits of quitting. ${ }^{15}$

Several studies address the relative impact of warning labels that do not meet minimum international standards, ${ }^{16-18}$ and make recommendations for novel content and locations for warning statements. ${ }^{19}{ }^{20}$ In a multicountry survey, pictorial warnings improve smokers' awareness of quitlines and cessation websites, moreso when the information appeared on both the front and back panels. ${ }^{18}$ This issue includes the first pictorial warning about the economic impact of smoking which tested well with adolescents and young adults in Lebanon, ${ }^{19}$ and would likely resonate with other target audiences, particularly low-income smokers. In addition, a pilot study finds that warnings printed on cigarette sticks increase smokers' intention to quit, ${ }^{20}$ which suggests new potential for reinforcing effects of on-pack warnings with novel, on-product messages.

\section{Retail displays and advertising}

Three studies examine the efficacy of display bans or smokers' support for such policies. In Western Australia, a display ban reduces the proportion of smokers who reported making an unplanned purchase. ${ }^{21}$ A majority of smokers in New Zealand favour a display ban prior to implementation, and support increased to $80 \%$ after 1 year from implementation. ${ }^{22}$ In three annual surveys, a majority of smokers in New York City do not favour a tobacco display ban, ${ }^{23}$ which illustrates a need for research about how to frame the benefits of a display ban in contexts where retail tobacco advertising persists.

\section{REGULATING THE BUILT ENVIRONMENT}

Comparatively few studies in this e-issue address policies to limit the quantity, type or location of tobacco retailers. ${ }^{23-27} \mathrm{~A}$ geospatial study about illegal sales to minors in Washington $\mathrm{DC}^{25}$ contributes to a growing body of evidence that proximity of tobacco retailers to schools affects youth access. ${ }^{28} 29$ In addition, poor adherence to a ban on tobacco sales near schools is documented in Mumbai, and exposure to retail tobacco marketing is a risk factor for tobacco use by students. $^{27}$ In the absence of comprehensive marketing restrictions, regulating the number, type and location of tobacco retailers could minimise the impact of retail marketing on initiation, cessation and relapse. ${ }^{3031}$ However, a majority of New York City adults favour only three of six proposals to regulate the built environment: limiting the number of retailers allowed to sell tobacco, prohibiting tobacco sales in pharmacies and at stores located near schools. ${ }^{23}$

Studies from New Zealand consider other policy solutions, such as regulating the source of duty-free tobacco sales, ${ }^{26}$ and compare the likely impact of eliminating sales within 1 or $2 \mathrm{~km}$ of schools, restricting sales to half of the liquor stores, and reducing the number of tobacco retailers by $95 \% .^{24}$ Future research should evaluate existing retailer reduction strategies, such as policies in Hungary $^{32}$ and San Francisco, ${ }^{33}$ as well as use agent-based modelling and other simulations to predict the impact of regulating the built environment on initiation, cessation and tobacco use disparities. 


\section{REGULATING THE RETAIL ENVIRONMENT FOR VAPOUR PRODUCTS}

With few exceptions, this issue focuses on combustible cigarettes. The prevalence of advertising for electronic cigarettes in a predominantly African-American neighbourhood of New York City ${ }^{34}$ highlights growing concerns that industry marketing strategies for these products mimic the promotion of menthol cigarettes and other flavoured tobacco products. ${ }^{35}$ In addition, a demonstration study finds that crowdsourcing and in-store photographs are useful to assess reliably the availability and advertising of e-cigarettes at the point of sale. ${ }^{36}$ In many countries, the growing prevalence of vape shops, which sell ecigarettes and other vapour products exclusively, ${ }^{37} 38$ is evidence of dramatic change in the retail environment for tobacco products. The quantity, location and regulation of vape shops are not well documented. Particularly in countries where vape shop workers mix solutions that contain liquid nicotine on site, and permit customer sampling, this new retail environment warrants research to protect worker and customer safety, to restrict youth access, and to regulate products and marketing that may be attractive to youth.

Competing interests $\mathrm{LH}$ is funded by the National Institutes of Health ( $\mathrm{NCl})$, the Tobacco-Related Disease Research Program, and the California Department of Public Health.

Provenance and peer review Commissioned; internally peer reviewed.

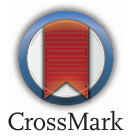

To cite Henriksen L. Tob Control 2015;24:e1-e2.

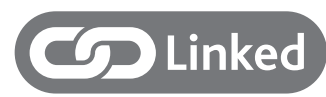

- http://dx.doi.org/10.1136/tobaccocontrol-2013-

051055

Tob Control 2015:24:e1-e2.

doi:10.1136/tobaccocontrol-2014-051884

\section{REFERENCES}

1 Center for Public Health Systems Science. Point-of-sale report to the nation: the tobacco retail and policy landscape. St. Louis, MO: Center for Public Health Systems Science at the Brown School at Washington University in St. Louis and the National Cancer Institute, State and Community Tobacco Control Research Initiative, 2014.

2 Henriksen L, Feighery EC, Schleicher NC, et al. Reaching youth at the point of sale: cigarette marketing is more prevalent in stores where adolescents shop frequently. Tob Control 2004;13:315-18

3 Apollonio DE, Malone RE. The "We Card" program: tobacco industry "youth smoking prevention" as industry self-preservation. Am J Public Health 2010;100:1188-201.

4 U.S. Department of Health and Human Services. The health consequences of smoking: 50 years of progress: a report of the surgeon general. Atlanta, GA: US Department of Health and Human Services, Centers for Disease Control Prevention and Health Promotion, Office of Smoking and Health, 2014.

5 Chapman S, Freeman B. Regulating the tobacco retail environment: beyond reducing sales to minors. Tob Control 2009;18:496-501.

6 McDaniel PA, Malone RE. "People over profits": retailers who voluntarily ended tobacco sales. PLOS ONE 2014;9;e85751. . eCollection 2014

7 Canadian Cancer Society. Cigarette package health warnings: international status report. 4th edn. September 2014

8 Wakefield MA, Germain D, Durkin SJ. How does increasingly plainer cigarette packaging influence adult smokers' perceptions about brand image? An experimental study. Tob Control 2008;17: 416-21.

9 Diethelm P, McKee M. Tobacco industry-funded research on standardised packaging: there are none so blind as those who will not see! Tob Control 2015;24:e113-5.

10 Bayly M, Scollo M, Wakefield M. No lasting effects of plain packaging on cigarette pack retrieval time in small Australian retail outlets. Tob Control 2015;24: e108-9.

11 Scollo M, Bayly M, Wakefield M. Availability of illicit tobacco in small retail outlets before and after the implementation of Australian plain packaging legislation. Tob Control 2015;24:e45-51.

12 Greenland SJ. Cigarette brand variant portfolio strategy and the use of colour in a darkening market. Tob Control 2015;24:e65-71.

13 Scollo M, Occleston J, Bayly M, et al. Tobacco product developments coinciding with the implementation of plain packaging in Australia. Tob Control 2015;24:e116-22.

14 Gallopel-Morvan K, Moodie C, Eker F, et al. Perceptions of plain packaging among young adult roll-your-own smokers in France: a naturalistic approach. Tob Control 2015;24:e39-44.

15 Mays D, Niaura RS, Evans WD, et al. Cigarette packaging and health warnings: the impact of plain packaging and message framing on young smokers. Tob Control 2015;24:e87-92.

16 Moodie C, Mackintosh AM, Hastings G. Adolescents' response to pictorial warnings on the reverse panel of cigarette packs: a repeat cross-sectional study. Tob Control 2015;24:e93-7.

17 Cameron LD, Pepper JK, Brewer NT. Responses of young adults to graphic warning labels for cigarette packages. Tob Control 2013;26:26.

18 Thrasher JF, Osman A, Moodie C, et al. Promoting cessation resources through cigarette package warning labels: a longitudinal survey with adult smokers in Canada, Australia and Mexico. Tob Control 2015;24:e23-31.

19 Alaouie H, Afifi RA, Haddad P, et al. Effectiveness of pictoral health warnings on cigarette packs among Lebanese school and university students. Tob Control 2015;24:e72-80.

20 Hassan LM, Shiu E. No place to hide: two pilot studies assessing the effectiveness of adding a health warning to the cigarette stick. Tob Control 2015;24: e3-5.
21 Carter $\mathrm{OB}$, Phan T, Mills BW. Impact of a point-of-sale tobacco display ban on smokers' spontaneous purchases: comparisons from postpurchase interviews before and after the ban in Western Australia. Tob Control 2015;24:e81-6.

22 Li J, Walton D. The immediate and long-term changes in support of tobacco display ban after its implementation in New Zealand. Tob Control 2015;24:e98-9.

23 Farley SM, Coady MH, Mandel-Ricci J, et al. Public opinions on tax and retail-based tobacco control strategies. Tob Control 2015;24:e10-3.

24 Pearson $A L$, van der Deen FS, Wilson $N$, et al. Theoretical impacts of a range of major tobacco retail outlet reduction interventions: modelling results in a country with a smoke-free nation goal. Tob Control 2015;24:e32-8.

25 Kirchner TR, Villanti AC, Cantrell J, et al. Tobacco retail outlet advertising practices and proximity to schools, parks and public housing affect Synar underage sales violations in Washington, DC. Tob Control 2015:24:e52-8.

26 Tautolo ES, Edwards R, Gifford H. A gift and a burden: the purchase and distribution of duty-free tobacco and its potential impact upon Pacific people in New Zealand. Tob Control 2015;24:e59-64.

27 Mistry R, Pednekar M, Pimple S, et al. Banning tobacco sales and advertisements near educational institutions may reduce students' tobacco use risk: evidence from Mumbai, India. Tob Control 2015;24:e100-7

28 Lipton R, Banerjee A, Levy D, et al. The spatial distribution of underage tobacco sales in Los Angeles. Subst Use Misuse 2008;43:1594-614.

29 Leatherdale ST, Strath JM. Tobacco retailer density surrounding schools and cigarette access behaviors among underage smoking students. Ann Behav Med 2007;33:105-11.

30 IOM (Institute of Medicine). Ending the tobacco problem: a blueprint for the nation. Washington DC: The National Academies Press, 2007.

31 Henriksen L. Comprehensive tobacco marketing restrictions: promotion, packaging, price and place. Tob Control 2012;21:147-53.

32 Caceres L, Chaiton M. Hungary: state licensing for tobacco outlets. Tob Control 2013;22:292-3.

33 Sabatini J. SF approves 50 percent reduction in tobacco-selling stores. The Examiner [newspaper online]. 10 December 2014. http://www.sfexaminer. com/sanfrancisco/sf-approves-50-percent-reduction-intobacco-selling-stores/Content?oid=2913907

34 Ganz 0, Cantrell J, Moon-Howard J, et al. Electronic cigarette advertising at the point-of-sale: a gap in tobacco control research. Tob Control 2015;24:e110-2.

35 Durbin RJ, Waxman HA, Harkin T, et al. Gateway to addiction? A survey of popular electronic cigarette manufacturers and targeted marketing to youth [Internet]; 14 April 2014 (cited 26 January 2015). http:/l www.durbin.senate.gov/public/index.cfm/files/serve/? File_id=81d14ff7-f2f6-4856-af9d-c20c0b138f8f

36 Kim AE, Lieberman AJ, Dench D. Crowdsourcing data collection of the retail tobacco environment: case study comparing data from crowdsourced workers to trained data collectors. Tob Control 2015;24:e6-9.

37 Lee YO, Kim AE. 'Vape shops' and 'E-Cigarette lounges' open across the USA to promote ENDS. Tob Control 2014. In press.

38 Sussman S, Garcia R, Cruz TB, et al. Consumers' perceptions of vape shops in Southern California: an analysis of online Yelp reviews. Tob Induc Dis 2014;12:014-0022. 